\title{
Microbial colonization of the lower airways after insertion of a cuffed endotracheal tube in pediatric patients
}

\author{
TOMAS KONDRATAS ${ }^{1}$, VAIDOTAS GURSKIS ${ }^{1}$, RIMANTAS KEVALAS ${ }^{1}$ ASTRA VITKAUSK- \\ IENE ${ }^{2}$, DOVILE EVALDA GRINKEVICIUTE ${ }^{1}$, LAIMUTE VAIDELIENE 3
}

\author{
${ }^{1}$ Paediatric intensive care unit, Department of Paediatrics, Lithuanian University of Health \\ Sciences, Eiveniu str. 2, LT-50009 Kaunas, Lithuania, www.kaunoklinikos.lt \\ ${ }^{2}$ Department of Laboratory Medicine, Hospital of Lithuanian University of Health Sciences, \\ Eiveniu str. 2, LT-50009 Kaunas, Lithuania, www.kaunoklinikos.lt \\ ${ }^{3}$ Paediatric pulmonology sector, Department of Paediatrics, Lithuanian University of Health \\ Sciences, Eiveniu str. 2, LT-50009 Kaunas, Lithuania, www.kaunoklinikos.lt \\ Abbreviated Title: Colonization of lower airways in intubated paediatric patients
}

Corresponding author:

Tomas Kondratas,

Paediatric Intensive Care Unit,

Department of Paediatrics, Lithuanian University of Health Sciences

Eiveniu str. 2, LT-50009 Kaunas, Lithuania,

Phone: +37037326038 , Fax: +37037327160 ,

e-mail: tomaskondratas@gmail.com

\section{ABSTRACT}

Background. Ventilator-associated pneumonia (VAP) still remains a common device-associated hospital acquired infection in pediatric and adult intensive care units. The aim of our study was to determine ways of microbial transmission to the lower airways in intubated patients admitted to a single tertiary-care pediatric intensive care unit.

Methods. This was a prospective observational study. A total of 284 sample sets (oropharyngeal swabs, swabs from the lumen of the proximal tip of an endotracheal tube, and bronchoalveolar lavage samples) were collected from 62 consecutive pediatric patients intubated for $>24$ hours. Pulsed-field gel electrophoresis was performed on all isolated pathogens, which were later identified by MALDI biotyper (MALDI-TOF mass spectrometry).

Results. Overall colonization rates were high and did not differ significantly at different time points in the oropharynx $(75 \%-100 \%)$ and the lower airways $(50 \%-$ $76.5 \%)$. The endotracheal tube was colonized at lower rates: on day 1-3 (28.8\%), on day 4-6 (52.7\%), on day 7-9 (61.8\%) and on day $10-12(52.9 \%)(\mathrm{P}<0.001)$. A total of 191 matched sample sets from the lower airways and at least one site above were collected from 46 (74.2\%) patients. In the oropharynx-lower airways group,
Candida spp. (76.9\%) and upper airway bacteria (63.2\%); in the endotracheal tubelower airway group, S. aureus (15.7\%) and upper airway bacteria $(21.1 \%)$; in the oropharynx-endotracheal tube-lower airway group, Enterobacteriaceae (70.8\%) prevailed $(\mathrm{P}<0.001)$. The mean survival (entrance) time to lower airways for the Acinetobacter / Pseudomonas / Stenotrophomonas group was $8.28 \pm 0.81$ days; for the Enterobacteriaceae group, $5.63 \pm$ 0.41; and for Candida spp. group, $3.00 \pm$ 0.82 days $(\mathrm{P}<0.005)$.

Conclusions. Oropharyngeal contamination of the lower airways is the most important route of colonization. Different pathogens enter the lower airways at different time intervals from the insertion of an endotracheal tube.

Keywords: colonization, airway, intubation, mechanical ventilation, bronchoalveolar lavage, ventilator-associated pneumonia

\section{INTRODUCTION}

Ventilator-associated pneumonia (VAP) still remains a common device-associated hospital acquired infection in pediatric and adult intensive care units (ICUs). During the last decade, a remarkable decline in the VAP incidence has been documented in economically developed countries; however, the incidence in developing countries is decreasing as well (1). Despite signifi- cant improvements, there is still a lot of controversy on how to achieve minimal incidence, even knowing the pathogenesis of colonization of the tracheal bronchial tree (2-4). Sometimes the implementation of VAP prevention bundles in the pediatric population is problematic. Likewise, elevation of the head by $300-450$ angle for an infant is even impossible, and deep vein thrombosis prophylaxis in the pediatric population does not work in terms of VAP prevention. Education and training of nursing staff and implementation of adjusted "pediatric" bundles have a significant impact on reduction in the VAP incidence (5). However, having a minimal incidence, there is still a question whether we can do something more. Therefore, the aim of our study was to determine ways of bacterial transmission to the lower airways (LA) and associated risk factors in intubated patients after the implementation of VAP prevention bundle in a tertiary-care pediatric intensive care unit (PICU).

\section{METHODS}

\section{Study population and data collection}

This prospective observational study was conducted in a single tertiary-care PICU (8 beds, around 50 patients intubated for $>24$ hours annually) of the Hospital of Lithuanian University of Health Sciences Kauno Klinikos from February 2012 to June 2013. All consecutive patients aged from 1 
month to 18 years and intubated for $>24$ hours were eligible for inclusion into the study. Exclusion criteria were multiple congenital abnormalities, chronic infection (e.g. cystic fibrosis), and mental disorders. Patients exited the study at time of extubation, tracheostomy, and death. None refused to participate in the study. The study protocol was approved by Kaunas Regional Biomedical Research Ethics Committee and written informed consent was obtained on January 9, 2012 (registration No. 8/2012).

According to the protocol, microbiological specimens were collected from three sites: oropharynx (OPX) (swabs), lumen of the proximal tip of an endotracheal tube (ETT) (swabs), and LA (bronchoalveolar lavage $[\mathrm{BAL}]$ aspirate). The blind BAL sample was taken by inserting a single-lumen regular endotracheal suction catheter of appropriate size through an orally inserted endotracheal tube. Patients were preoxigenated with $100 \%$ oxygen. Then a suction catheter was inserted to a wedge position, instilling $1 \mathrm{~mL} / \mathrm{kg}$ saline for $<20 \mathrm{~kg}$ and 20 $\mathrm{mL}$ saline for $>20 \mathrm{~kg}$ patient, and then immediately withdrawing the fluid (6-8). Any count of pathogens $(\mathrm{cfu} / \mathrm{mL})$ in LA was considered as positive, and BAL aspirate with $\geq 105 \mathrm{cfu} / \mathrm{mL}$ was defined as heavy colonization (9). The oropharynx was chosen because its crossroad position for the nasopharynx, oral cavity, and hypopharynx and potential endogenous source, and proximal tip of the ETT because of its potential exogenous source of contamination and colonization of the tracheal bronchial tree $(1 ; 3 ; 4 ; 10)$. Sets of three microbiological samples were collected on the first day and every third consecutive day until day 18 and later every fifth day until day 28. Extra sample sets were taken in the following seven circumstances: 1) before extubation, 2) after bronchoscopy, 3) gastrointestinal endoscopy and after patient transportation for investigation such as 4) computed tomography (CT), 5) magnetic resonance imaging (MRI), and 6) other or 7) surgery outside the PICU area. A total of 284 sample sets $(284 \times 3$ samples $)$ were collected for 62 patients.

\section{Microbiologic methods}

Study samples were coded and sent to the microbiology laboratory for identification. The samples were inoculated directly onto 5\% sheep blood agar (BBL, USA), chocolate agar (BBL, USA), and MacConkey agar plates (Oxoid, UK). Sheep blood and chocolate agar plates were incubated at $35^{\circ} \mathrm{C}$ in an atmosphere containing $5 \%$ $\mathrm{CO} 2$ and MacConkey agar plates, at $35^{\circ} \mathrm{C}$ for 18-24 hours. If a culture was negative on the first observation, sheep blood and chocolate agar plates were re-examined after the second 24-hour incubation. Pulsedfield gel electrophoresis (PFGE) was performed on all isolated pathogens by using the modified procedures published by Barth and Pitt as well as Grothues and Tümmler $(10 ; 11)$. Isolated pathogens, potentially causing VAP, and others (S. pneumoniae, $\mathrm{H}$. influenzae, $\mathrm{S}$. aureus, E. coli, $\mathrm{K}$. pneumoniae, Enterobacter cloacae, Enterococcus spp., P. aeruginosa, Acinetobacter spp., Stenotrophomonas maltophilia, Candida spp., beta-hemolytic streptococci) were identified using matrix-assisted laser desorption ionization-time of flight (MALDI-TOF, Bruker) mass spectrometry (MS). Disk diffusion susceptibility testing was performed, and zone diameters of inhibition were interpreted according to the European Committee on Antimicrobial Susceptibility Testing (EUCAST) recommendations.

\section{VAP definition and prevention in the PICU}

VAP was identified during the routine surveillance procedure by using a combination of imaging, clinical, and laboratory criteria (pathogen concentration of $\geq 104$ $\mathrm{cfu} / \mathrm{mL}$ in a blind BAL aspirate). Ventilator-associated tracheobronchitis (VAT) diagnosis was based on the absence of clinical and radiographic evidence of pneumonia and the following criteria: positive culture obtained by deep tracheal aspirate and 2 signs or symptoms with no recognizable cause (fever $\left[>38.5^{\circ} \mathrm{C}\right]$, cough, new or increased sputum production, rhonchi, or wheezing) (12;13).

In the period from 2006 to 2007, when the multimodal intervention was designed (education of the PICU staff about VAP prevention and correction of daily care of a patient according to the evidence-based recommendations, feedback communication with the PICU staff in the postintervention period and implementation of new daily care protocols), there was a sharp decrease in the VAP incidence (21.8 versus 8.8 per 1000 ventilator-days) (14). Later, the implementation of VAP prevention bundle (semi-recumbent $30^{\circ}-45^{\circ}$ position of the head, daily evaluation of readiness to wean, comprehensive oral care protocol, periodical check for gastric overdistention, ETT cuff pressure between 20 and $30 \mathrm{~cm}$ of water, stress ulcer prophylaxis, periodic drainage and absence of tubing condensate and annual reporting of surveillance results in the PICU) led to a further decline in the VAP incidence curve (2.0 per 1000 ventilator-days in 2012; surveillance data were submitted to the INICC registry) (1).

\section{Statistical analysis}

First of all, all the microbiological samples were analyzed and later, matched sample sets. A matched sample set was defined if there was a growth of matching pathogens from the LA and at least one of the other upper airway sites (OPX or ETT) at the moment of sample collection. For statistical analysis, all the pathogens were divided into five groups: Acinetobacter, Pseudomonas and Stenotrophomonas (APS); Candida spp.; Enterobacteriaceae; S. aureus; and bacteria of the upper airway (UA) with the oral cavity.

The descriptive analysis methods were used (mean, standard deviation, median, interquartile range (IQR), proportion). Pediatric index of mortality (PIM2) was used as independent descriptive variable for assessment of status of a patient at the time of his admission to PICU or the first face-to-face contact with PICU physician (15). The crosstabulation method and the chi-square test with an estimate of adjusted residual ( $\geq|2.0|$ ) were used to compare categorical variables among different subgroups. In addition, matched samples were tested using Kaplan-Meier survival analysis and the Breslow test for pairwise comparisons. Survival time was defined as the time period between ETT placement and entry of a matching pathogen from the OPX or the ETT to the LA. For all analyses, $\mathrm{P}<0.05$ (2-tailed) was considered statistically significant.

\section{RESULTS}

Among 62 orally intubated patients, there were $40(64.5 \%)$ of males with a mean age of 7.3 years $(\mathrm{SD}=6.5)$ and $22(35.5 \%)$ of females with a mean age of 8.6 years $(\mathrm{SD}=7.2)$. The mean PIM2 was $10.8 \%$ (median, 4.8; IQR, 7.63) $(1 ; 15)$. Most of the patients' clinical characteristics are presented in Table 1.

The overall colonization rates were high and distributed homogeneously in the OPX $(75 \%-100 \% ;(\chi 2=5.35, \mathrm{df}=6, \mathrm{P}>$ $0.05)$ and the LA $(50 \%-76.5 \% ; \chi 2=6.85, \mathrm{df}$ $=6, \mathrm{P}>0.05)$. However, the ETT was colonized at lower rates and the colonization rates differed significantly $\left(22.2 \%-80 \% ; \chi^{2}\right.$ $=25.02, \mathrm{df}=6, \mathrm{P}<0.001)$. The lowest rate was observed on days $1-3(28.8 \%, \mathrm{AR}=-$ $4.2)$ and the highest, on days $4-6(52.7 \%$, $\mathrm{AR}=2.2)$, days 7-9 (61.8\%, $\mathrm{AR}=2.8)$ and days $10-12(52.9 \%, \mathrm{AR}=1.2)$ (Table 2). A total of $166(58.5 \%)$ BAL aspirates were 
Table 1. Clinical characteristics of patients

\begin{tabular}{|c|c|c|}
\hline & $\mathbf{N}$ & $\%$ \\
\hline \multicolumn{3}{|l|}{ Pathology and syndromes: } \\
\hline Trauma & 20 & 32.3 \\
\hline Neurologic diseases & 18 & 29.0 \\
\hline Sepsis & 10 & 16.1 \\
\hline Pneumonia and bronchiolitis & 7 & 11.3 \\
\hline Burns (skin and/or airways) & 5 & 8.1 \\
\hline Myocarditis & 1 & 1.6 \\
\hline Poisoning & 1 & 1.6 \\
\hline Respiratory failure & 43 & 69.4 \\
\hline Coma & 32 & 51.6 \\
\hline Shock & 19 & 30.6 \\
\hline Seizures & 10 & 16.1 \\
\hline Dehydration & 9 & 14.5 \\
\hline Multiple organ failure & 4 & 6.5 \\
\hline Disseminated intravascular coagulation & 2 & 3.2 \\
\hline Acute renal failure & 2 & 3.2 \\
\hline Acute hepatic failure & 2 & 3.2 \\
\hline Heart arrest & 2 & 3.2 \\
\hline \multicolumn{3}{|l|}{ Invasive and noninvasive procedures: } \\
\hline Urinary catheter & 55 & 88.7 \\
\hline Central venous catheter & 39 & 62.9 \\
\hline Head CT & 31 & 50.0 \\
\hline Arterial catheter & 23 & 37.1 \\
\hline Lumbar puncture & 16 & 25.8 \\
\hline Gastrointestinal endoscopy & 9 & 14.5 \\
\hline Therapeutic hypothermia $\left(33^{\circ} \mathrm{C}-34^{\circ} \mathrm{C}\right)$ & 7 & 11.3 \\
\hline Head MRI & 5 & 8.1 \\
\hline Bronchoscopy & 3 & 4.8 \\
\hline EEG & 2 & 3.2 \\
\hline Surgical operation: & 23 & 37.1 \\
\hline clean & 16 & 25.8 \\
\hline clean-contaminated or contaminated & 7 & 11.3 \\
\hline ICP probe & 6 & 9.7 \\
\hline \multicolumn{3}{|l|}{ Inotropic and vasoactive drugs: } \\
\hline Dopamine & 18 & 29.0 \\
\hline Norepinephrine & 5 & 8.1 \\
\hline Epinephrine & 4 & 6.5 \\
\hline Dobutamine & 3 & 4.8 \\
\hline Levosimendan & 1 & 1.6 \\
\hline
\end{tabular}

Table 2. Colonization rates by site and time period

\begin{tabular}{lllllll}
\hline & All samples & Sampleså & Extra samples & OPX & ETT & LA \\
\hline Days & $\mathrm{N}$ & $\mathrm{N}$ & $\mathrm{N}$ & Positive $\%$ & Positive $\%$ & Positive \% \\
\hline $1-3$ & 160 & 114 & 46 & 85.0 & 28.8 & 53.5 \\
\hline $4-6$ & 55 & 29 & 26 & 81.8 & 52.7 & 60.7 \\
\hline $7-9$ & 34 & 18 & 16 & 88.2 & 61.8 & 76.5 \\
\hline $10-12$ & 17 & 9 & 8 & 94.1 & 52.9 & 52.9 \\
\hline $13-15$ & 9 & 6 & 3 & 66.7 & 22.2 & 66.7 \\
\hline $16-18$ & 4 & 4 & 0 & 75.0 & 25.0 & 50.0 \\
\hline $19-28$ & 5 & 4 & 1 & 100 & 80.0 & 60.0 \\
\hline
\end{tabular}




\begin{tabular}{|c|c|c|c|c|c|c|c|c|c|c|c|c|c|c|c|c|}
\hline Isolate & Ant & micro & bial a & ent & & & & & & & & & & & & \\
\hline & 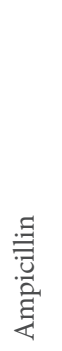 & 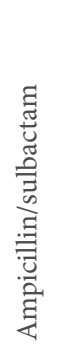 & 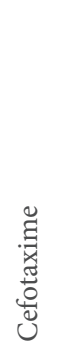 & 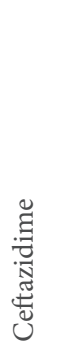 & 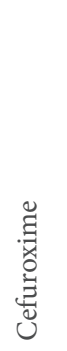 & 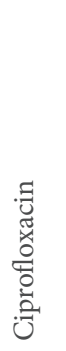 & 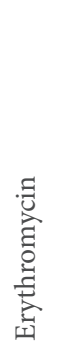 & 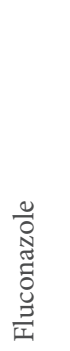 & 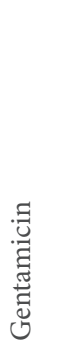 & 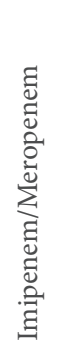 & 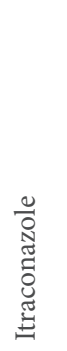 & 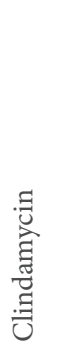 & 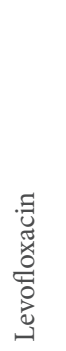 & 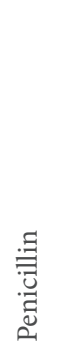 & 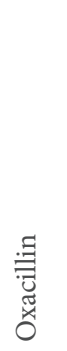 & 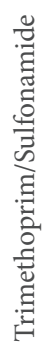 \\
\hline S. aureus $(\mathrm{n}=51)$ & & & & & & & & & & & & 100 & & & 100 & 100 \\
\hline Klebsiella spp. $(\mathrm{n}=31)$ & & & 83.9 & & & 96.8 & & & 83.9 & & & & & & & \\
\hline Enterobacter spp. $(\mathrm{n}=19)$ & & & 84.2 & & & 100 & & & 94.7 & & & & & & & \\
\hline Acinetobacter spp. $(\mathrm{n}=18)$ & & 100 & & 63.6 & & & & & & 100 & & & & & & \\
\hline E. $\operatorname{coli}(n=16)$ & & & 50 & & & 100 & & & 100 & & & & & & & \\
\hline Candida spp. $(\mathrm{n}=13)$ & & & & & & & & 92.3 & & & 92.3 & & & & & \\
\hline Beta-hemolytic streptococci $(\mathrm{n}=10)$ & & & & & & & 90 & & & & & 100 & & 100 & & \\
\hline S. maltophilia $(\mathrm{n}=10)$ & & & & 0 & & & & & & & & & 100 & & & 40 \\
\hline Pseudomonas spp. $(\mathrm{n}=8)$ & & & & 100 & & 100 & & & 87.5 & & & & & & & \\
\hline C. freundii $(\mathrm{n}=4)$ & & & 100 & & & 100 & & & 100 & & & & & & & \\
\hline S. pneumoniae $(\mathrm{n}=3)$ & & & & & & & 100 & & & & & 100 & & 100 & & \\
\hline Moraxella spp. $(\mathrm{n}=3)$ & 0 & & & & 100 & & & & & & & & & & & \\
\hline H. influenzae $(\mathrm{n}=2)$ & 50 & & & & 100 & & & & & & & & & & & \\
\hline P. mirabilis $(\mathrm{n}=1)$ & & & 100 & & & 100 & & & 100 & & & & & & & \\
\hline R. ornithinolytica $(\mathrm{n}=1)$ & & & 100 & & & 100 & & & 100 & & & & & & & \\
\hline E. corrodens $(n=1)$ & 100 & & & & 100 & & & & & & & & & & & \\
\hline
\end{tabular}

Table 4. Colonization rates by pathogen groups and matched sample groups

\begin{tabular}{|c|c|c|c|c|c|}
\hline Pathogen groups & n, \%, AR & OPX-LA & ETT-LA & OPX-ETT-LA & Total \\
\hline \multirow[t]{3}{*}{ APS } & $\mathrm{n}$ & 9 & 2 & 25 & 36 \\
\hline & proc. & 25.0 & 5.6 & 69.4 & 100 \\
\hline & $\mathrm{AR}$ & -1.1 & -0.8 & 1.5 & \\
\hline \multirow[t]{3}{*}{ Candida spp. } & $\mathrm{n}$ & 10 & 2 & 1 & 13 \\
\hline & proc. & 76.9 & 15.4 & 7.7 & 100 \\
\hline & $\mathrm{AR}$ & 3.5 & 0.9 & -3.9 & \\
\hline \multirow[t]{3}{*}{ Enterobacteriaceae } & $\mathrm{n}$ & 20 & 1 & 51 & 72 \\
\hline & proc. & 27.8 & 1.4 & 70.8 & 100 \\
\hline & $\mathrm{AR}$ & -1.1 & -2.8 & 2.7 & \\
\hline \multirow[t]{3}{*}{ S. aureus } & $\mathrm{n}$ & 11 & 8 & 32 & 51 \\
\hline & proc. & 21.6 & 15.7 & 62.7 & 100 \\
\hline & $\mathrm{AR}$ & -1.9 & 2.0 & 0.7 & \\
\hline \multirow[t]{3}{*}{ UA bacteria } & $\mathrm{n}$ & 12 & 4 & 3 & 19 \\
\hline & proc. & 63.2 & 21.1 & 15.8 & 100 \\
\hline & $\mathrm{AR}$ & 3.0 & 2.0 & -4.0 & \\
\hline \multirow[t]{2}{*}{ Total } & $\mathrm{n}$ & 62 & 17 & 112 & 191 \\
\hline & $\%$ & 32.5 & 8.9 & 58.6 & 100 \\
\hline
\end{tabular}

$\overline{\mathrm{AR}}$, adjusted residual. 
Table 5. Colonization rates by time period and matched sample groups

\begin{tabular}{|c|c|c|c|c|c|}
\hline Days & $\mathrm{n}, \%, \mathrm{AR}$ & OPX-LA & ETT-LA & OPX-ETT-LA & Total \\
\hline \multirow[t]{3}{*}{$1-3$} & $\mathrm{~N}$ & 42 & 10 & 35 & 87 \\
\hline & $\%$ & 48.3 & 11.5 & 40.2 & 100 \\
\hline & $\mathrm{AR}$ & 4.3 & 1.2 & -4.7 & \\
\hline \multirow[t]{3}{*}{$4-6$} & $\mathrm{~N}$ & 11 & 3 & 31 & 45 \\
\hline & $\%$ & 24.4 & 6.7 & 68.9 & 100 \\
\hline & $\mathrm{AR}$ & -1.3 & -0.6 & 1.6 & \\
\hline \multirow[t]{3}{*}{$7-9$} & $\mathrm{~N}$ & 1 & 2 & 32 & 35 \\
\hline & $\%$ & 2.9 & 5.7 & 91.4 & 100 \\
\hline & $\mathrm{AR}$ & -4.1 & -0.7 & 4.4 & \\
\hline \multirow[t]{3}{*}{$10-12$} & $\mathrm{~N}$ & 2 & 1 & 8 & 11 \\
\hline & $\%$ & 18.2 & 9.1 & 72.7 & 100 \\
\hline & $\mathrm{AR}$ & -1.0 & 0.02 & 1.0 & \\
\hline \multirow[t]{3}{*}{$13-15$} & $\mathrm{~N}$ & 4 & 0 & 5 & 9 \\
\hline & $\%$ & 44.4 & 0 & 55.6 & 100 \\
\hline & $\mathrm{AR}$ & 0.8 & -1.0 & -0.2 & \\
\hline \multirow[t]{2}{*}{$16-18$} & $\mathrm{~N}$ & 0 & 0 & 0 & 0 \\
\hline & $\%$ & 0 & 0 & 0 & 0 \\
\hline \multirow[t]{3}{*}{$19-28$} & $\mathrm{n}$ & 2 & 1 & 1 & 4 \\
\hline & $\%$ & 50 & 25 & 25 & 100 \\
\hline & $\mathrm{AR}$ & 0.8 & 1.1 & -1.4 & \\
\hline \multirow[t]{2}{*}{ Total } & $\mathrm{n}$ & 62 & 17 & 112 & 191 \\
\hline & $\%$ & 32.5 & 8.9 & 58.6 & 100 \\
\hline
\end{tabular}

$\mathrm{AR}$, adjusted residual.

Figure. Survival analysis of matched samples by pathogen groups

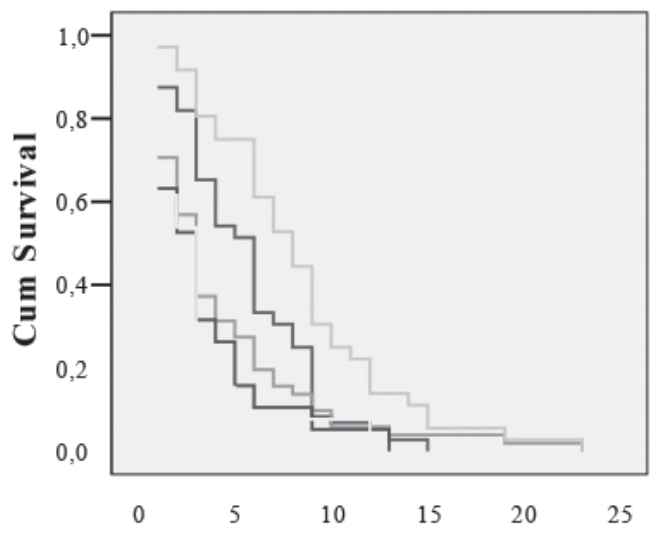

Enterobacteriaceae

S. aureus

APS

Upper airway

bacteria

Candida spp.

Day after ET tube placement

\begin{tabular}{|c|c|c|c|c|c|c|c|c|}
\hline \multirow[t]{2}{*}{ Pathogen groups } & \multicolumn{2}{|c|}{ All matches $(n=191)$} & \multicolumn{2}{|c|}{ OPX-LA $(n=62)$} & \multicolumn{2}{|c|}{ ETT-LA $(\mathrm{n}=17)$} & \multicolumn{2}{|c|}{ OPX-ETT-LA $(\mathrm{n}=112)$} \\
\hline & Mean & $\mathrm{SE}$ & Mean & SE & Mean & SE & Mean & SE \\
\hline Enterobacteriaceae & 5.63 & 0.41 & 3.50 & 0.64 & 3.00 & 0 & 6.51 & 0.47 \\
\hline S. aureus & 4.31 & 0.63 & 1.64 & 0.39 & 6.25 & 2.01 & 4.75 & 0.81 \\
\hline APS & 8.28 & 0.81 & 10.44 & 2.65 & 8.00 & 1.00 & 7.52 & 0.66 \\
\hline $\begin{array}{l}\text { Upper airway bac- } \\
\text { teria }\end{array}$ & 3.42 & 0.73 & 3.75 & 1.12 & 3.00 & 0.82 & 2.67 & 0.88 \\
\hline Candida spp. & 3.00 & 0.82 & 2.90 & 1.06 & 2.50 & 0.50 & 5.00 & 0 \\
\hline Overall & 5.38 & 0.31 & 4.13 & 0.61 & 5.06 & 1.05 & 6.12 & 0.36 \\
\hline
\end{tabular}


positive, and in 94 (56.6\%) of them, heavy colonization $(\geq 105 \mathrm{cfu} / \mathrm{mL})$ was observed. A total of 191 matched samples were collected from $46(74.2 \%)$ of the 62 patients. A triple OPX-ETT-LA sample set was seen in $112(58.6 \%)$ of all cases; double OPXLA, in 62 (32.5\%); and double ETT-LA, in 17 (8.9\%). The overall picture of colonizing pathogens and their antimicrobial susceptibility are presented in Table 3. S. aureus (26.7\%), Klebsiella spp. (16.2\%), Enterobacter spp. (10.0\%), Acinetobacter spp. (9.4\%), E. coli (8.4\%), and Candida spp. $(6.8 \%)$ prevailed in matched sample sets. Antimicrobial susceptibility rates of the majority of pathogens was high and ranged from $83.9 \%$ to $100 \%$ with the exception of Acinetobacter spp. susceptibility to ceftazidime (63.6\%), S. maltophilia susceptibility to ceftazidime $(0 \%)$ and trimethoprim/sulfonamide (40\%), and H. influenzae susceptibility to ampicillin (50\%).

The colonization rates by pathogen groups and matched sample groups were differently distributed $(\chi 2=42.22, \mathrm{df}=8, \mathrm{P}<$ $0.001)$. In the OPX-LA group, Candida spp. (76.9\%) and UA bacteria (63.2\%); in the ETT-LA group, S. aureus (15.7\%) and UA bacteria (21.1\%); and in the OPX-ETT-LA group, Enterobacteriaceae $(70.8 \%)$ were most frequently observed (Table 4). Analysis of colonization rates by different pathogens showed a very similar pattern: Candida spp. (76.9\%) prevailed in the OPX-LA group; S. aureus (15.7\%), in the ETT-LA group; and Klebsiella spp. (77.4\%), in the OPX-ETT-LA group $(\chi 2=59.01, \mathrm{df}=30$, $\mathrm{P}<0.001)$. A total of $106(55.5 \%) \mathrm{BAL}$ aspirates were heavily colonized ( $\geq 105 \mathrm{cfu}$ / $\mathrm{mL}$ ). There was a monomicrobial growth in the OPX and the ETT in almost twothirds of the matched sample sets $(n=123$, $64.4 \%$ ), but a polymicrobial growth was also observed $(n=68,35.6 \%)$. Mono and polymicrobial growth was steady over time $(\chi 2=3.39, \mathrm{df}=5, \mathrm{P}>0.05)$.

There were one VAP (OPX-ETT-LA) and five VAT (OPX-ETT-LA - 4, OPX- LA 1) cases in the matched sample group. A single case of VAP was caused by P. aeruginosa, and VAT, by S. aureus $(\mathrm{n}=2)$, Acinetobacter spp. $(n=1)$, C. freundii $(n=1)$ and Klebsiella spp. $(\mathrm{n}=1)$.

The colonization rates by time groups and matched sample groups significantly differed $\left(\chi^{2}=35.20, \mathrm{df}=10, \mathrm{P}<0.001\right)$. The occurrence of OPX-LA matched cases (48.2\%) was significant on days $1-3$. However, OPX-ETT-LA cases were frequently observed throughout almost all the periods ( $\geq 25 \%$ ), and on days $1-3$ and $7-9$ $(40.2 \%$ and $91.4 \%$, respectively) its occurrence was significant. There were no matched samples on days 16-18 (Table 5). The occurrences of matched samples were not associated with eight circumstances (one planned and seven extra) for sample collection $(\chi 2=22.11, \mathrm{df}=14, \mathrm{P}>$ $0.05)$. The overall distribution of the first matched cases in matched sample groups by eight reasons was also homogeneous $(\chi 2=20.77, \mathrm{df}=12, \mathrm{P}=0.05)$, however, the occurrence of the first OPX-LA case was significantly associated with transportation for a CT scan outside the PICU area $(\mathrm{n}=6,100 \%, \mathrm{AR}=2.1)$.

Overall survival analysis of matched samples showed that the mean survival time was the longest for APS (8.28 days, 95\% CI 6.69-9.86) in pairwise comparisons between five pathogen groups, was shorter for Enterobacteriaceae (5.63 days, 95\% CI 4.82-6.43), S. aureus (4.31 days, 95\% CI 3.08-5.55) and UA bacteria (3.42 days, 95\% CI 2.00-4.85); and the shortest for Candida spp. (3.00 days, 95\% CI 1.384.62) $(\mathrm{P}=0.001-0.005)$ (Figure).

Subgroup analysis also showed that the mean survival time in the OPX-LA subgroup was longest for APS (10.44 days, 95\% CI 5.25-15.64) when five pathogen groups were compared ( $\mathrm{P}=0.01-0.029)$. The mean survival time for Enterobacteriaceae (3.50 days, 95\% CI 2.25-4.75) and Candida spp. (2.90 days, 95\% CI $0.83-4.98)$ was shorter $(\mathrm{P}=0.01-0.029)$; and for $\mathrm{S}$. aureus, the shortest one (1.64 days, 95\% CI 0.88-2.40) ( $\mathrm{P}=0.001-0.01)$. In the ETT-LA subgroup, there were no significant differences in the mean survival times comparing the groups by pathogens. In the OPX-ETT-LA subgroup, the mean survival time for APS was the longest (7.52 days, 95\% CI 6.2-8.81); for Enterobacteriaceae (6.51 days, 95\% CI 5.5-7.43) and S. aureus (4.75 days, 95\% CI 3.16-6.34) shorter; and for UA bacteria, the shortest one (2.67 days, 95\% CI 0.94-4.40) ( $\mathrm{P}=$ 0.001-0.009).

\section{DISCUSSION}

The strength of this study was that it was conducted in the PICU and exclusively patients with ETTs were enrolled. An overall LA colonization rate was varied from 50\% to $76.6 \%$, and in more than $50 \%$ of the cases, a bacterial count exceeded the threshold of heavy colonization. In most (74.2\%) of the participants, matching microorganisms were detected in the LA and the OPX or/and the ETT. Interestingly, Enterobacteriaceae were most frequently observed in the OPX-ETT-LA group, giving an explanation that colonization in the OPX leads to LA colonization and secondary contamination of the ETT. A proximal tip of the ETT was less frequently colonized, and there were no nonfermenting gram-negative bacteria (Pseudomonas spp., Acinetobacter spp., S. maltophilia) in the ETT-LA matching pathogen group. The presence of $S$. aureus and UA bacteria in the tube most likely shows its secondary contamination from the LA, because UA bacteria and Candida spp. at high rates and S. aureus at lower rates were most frequently seen in the OPX-LA group. Associations between a high colonization rate in the OPX and its significance in matching group formation suggest that the OPX was the most important initial site before LA colonization.

LA colonization starts from the time of intubation and continues over time $(16 ; 17)$. In our study, the LA were already colonized at a rate of $>50 \%$ during the first period (days 1-3) and the colonization rate was stable through all periods. In almost two-thirds of the matched cases, there was a monomicrobial growth in the OPX and the ETT, and it was steady over time. Therefore, we partially agree with Berdal et al., who proposed to use oropharyngeal swab surveillance data to guide empirical antimicrobial therapy for VAP cases in the ICU (17). However, in one-third of the cases, in the presence of polymicrobial growth and different combinations of pathogens in OPX, a clinician can be mistaken.

Survival analysis revealed that Candida spp. reached the LA from the OPX during 1.38-4.62 days on average; Enterobacteriaceae, during 4.82-6.43 days; and; nonfermenting gram-negative bacteria during 6.69-9.86 days. Most likely in absolute majority of the cases, insertion of the ETT allowed Candida spp. direct access to the LA from the OPX, because the mean survival time was the shortest. We cannot confirm entry of other pathogens to the LA at the moment of oral endotracheal intubation. We suggest their later entry to the LA, even entry of UA and S. aureus, based on the results of survival analysis in latter subgroups.

Analysis of the reasons for sample collection or risk factors for LA colonization has showed that occurrence of the first matching OPX-LA case was associated with transportation for a CT scan outside the PICU. This could be explained by increased leakage near the cuff due to slight movements of the ETT during transportation, suggesting better preventive oropharyngeal and deep hypopharyngeal suctioning of secretions and cuff pressure monitoring before transportation of patients in the future. 
In the literature, there is an ongoing debate about the importance of LA colonization while an intubated patient stays in the ICU $(4 ; 9 ; 18)$. Colonization, VAT, and VAP seems to be integral parts of one process $(9 ; 19)$. In our study, only few cases of VAT and VAP were diagnosed. A single VAP case met the criteria; however, only one VAT case met the criteria described by Craven et al., because we did not use the quantitative criteria defining VAT in our surveillance system $(4 ; 12 ; 18)$. Risk factors for VAP are well described and preventive bundles have been proposed based on these data (20-22). However, leakage near the endotracheal cuff remains the main bridge between the OPX and the LA, causing colonization, VAT, and VAP. Prevention of leakage still remains a big challenge in the care of a critically ill patient (5). In the PICU, cuff pressure measurements are crucial $(5 ; 23 ; 24)$, because an application of subglotic secretion drainage (SSD) is limited due to smaller tube sizes used (ETT tubes $<5 \mathrm{~mm}$ in diameter with a SSD port are not produced), despite evidence about SSD benefit in VAP prevention. The clinical benefit of ETT with taper-shaped cuffs and silver-coated ETT still needs to be proved $(5 ; 25)$.

Interestingly, in our study we have not detected highly resistant or multidrug-resistant pathogens in the LA, and an overall antimicrobial susceptibility picture was even better than we expected. Limitation of our study is that we have not investigated the influence of antimicrobials on the colonization of OPX, ETT, and LA. However, we are sure that our colonization data cannot be biased by antimicrobials, because OPX and LA colonization rates remained steady over a study time and antimicrobial susceptibility rates were high and mortality rate was low, indicating efficacy of the antimicrobial stewardship program in the PICU.

In conclusion, oropharyngeal contamination of the lower airways is the most important route of colonization. Different pathogens enter the lower airways at different time intervals from the moment of endotracheal tube placement. Reduction of leakage near the endotracheal cuff remains challenging in the PICU, and meticulous care of the oropharynx and endotracheal cuff pressure monitoring are advised before transportation of an intubated patient.

\section{ACKNOWLEDGMENTS}

We highly appreciate PICU nurses and laboratory technicians for their kindness and considerable contribution to this study.

\section{REFERENCES}

1. Rosenthal VD, Al-Abdely HM, El-Kholy AA, AlKhawaja SA, Leblebicioglu H, Mehta Y, et al. International Nosocomial Infection Control Consortium report, data summary of 50 countries for 2010-2015: Device-associated module. Am J Infect Control 2016 Oct 11.

2. Craven DE, Lei Y, Ruthazer R, Sarwar A, Hudcova J. Incidence and outcomes of ventilator-associated tracheobronchitis and pneumonia. Am J Med 2013 Jun;126(6):542-9.

3. Fernandez JF, Levine SM, Restrepo MI. Technologic advances in endotracheal tubes for prevention of ventilator-associated pneumonia. Chest 2012 Jul;142(1):231-8.

4. Palmer LB. Ventilator-associated infection. Curr Opin Pulm Med 2009 May;15(3):230-5.

5. Blot SI, Poelaert J, Kollef M. How to avoid microaspiration? A key element for the prevention of ventilator-associated pneumonia in intubated ICU patients. BMC Infect Dis 2014 Nov 28;14:119.

6. Burmester M, Mok Q. How safe is non-bronchoscopic bronchoalveolar lavage in critically ill mechanically ventilated children? Intensive Care Med 2001 Apr;27(4):716-21.

7. de BJ, Midulla F, Barbato A, Clement A, Dab I, Eber E, et al. Bronchoalveolar lavage in children. ERS Task Force on bronchoalveolar lavage in children. European Respiratory Society. Eur Respir J 2000 Jan;15(1):217-31.

8. Foglia E, Meier MD, Elward A. Ventilator-associated pneumonia in neonatal and pediatric intensive care unit patients. Clin Microbiol Rev 2007;20(3):409-25.

9. Craven DE, Hjalmarson KI. Ventilator-associated tracheobronchitis and pneumonia: thinking outside the box. Clin Infect Dis 2010 Aug 1;51 Suppl 1:S59-S66.

10. Barth AL, Pitt TL. Auxotrophy of Burkholderia (Pseudomonas) cepacia from cystic fibrosis patients. J Clin Microbiol 1995 Aug;33(8):2192-4.

11. Grothues D, Tummler B. New approaches in genome analysis by pulsed-field gel electrophoresis: application to the analysis of Pseudomonas species. Mol Microbiol 1991 Nov;5(11):2763-76.

12. Centers for Disease Control and Prevention. Guidelines for preventing health-care-associated pneumonia 2008. 2016. http://www. cdc.gov/nhsn/pdfs/pscmanual/6pscvapcurrent.pdf.

13. Kalil AC, Metersky ML, Klompas M, Muscedere J, Sweeney DA, Palmer LB, et al. Management of Adults With Hospital-acquired and Ventilator-associated Pneumonia: 2016 Clinical Practice Guidelines by the Infectious Diseases Society of America and the American Thoracic Society. Clin Infect Dis 2016 Sep 1;63(5):e61-e111.

14. Gurskis V, Asembergiene J, Kevalas R, Miciuleviciene J, Pavilonis A, Valinteliene R, et al. Reduction of nosocomial infections and mortality attributable to nosocomial infections in pediatric intensive care units in Lithuania. Medicina (Kaunas) 2009;45(3):203-13.

15. Slater A, Shann F, Pearson G, PIM Study Group. PIM2: a revised version of the Paediatric Index of Mortality. Intensive Care Med 2003;29(2):278-85.

16. Agvald-Öman C. Colonization, infection and dissemination in intensive care patients [dissertation]. Stockholm: Karolinska Institutet; 2007.

17. Berdal JE, Bjornholt J, Blomfeldt A, Smith-Erichsen N, Bukholm G. Patterns and dynamics of airway colonisation in mechanicallyventilated patients. Clin Microbiol Infect 2007 May;13(5):476-80.

18. Craven DE, Hudcova J, Lei Y. Diagnosis of ventilator-associated respiratory infections (VARI): microbiologic clues for tracheobronchitis (VAT) and pneumonia (VAP). Clin Chest Med 2011 Sep;32(3):547-57. 
